\title{
Benign Familial Convulsion
}

National Cancer Institute

\section{Source}

National Cancer Institute. Benign Familial Convulsion. NCI Thesaurus. Code C117307.

A group of genetically-determined conditions characterized by a wide spectrum of seizure types occurring in otherwise healthy newborn infants that start during the first week of life and spontaneously disappear between the first and twelfth months of life. 